\title{
The fundamental review of the trading book and the quest for a sound prudential framework for trading activities
}

\author{
Juan Segurado Escudero \\ Técnico Comercial y Economista del Estado
}

\begin{abstract}
The purpose of the fundamental review of the trading book (2016) was to overcome the conceptual shortcomings of the previous prudential framework, which were revealed during the crisis (2007-2012). In the article, the main features of this new framework are described, compared to the old one and assessed against its original objectives. In general, most changes and innovations have sound theoretical foundations and hence a strong potential to achieve the intended objectives, such as increasing risk-sensitivity, reducing undue risk-weight variability or limiting regulatory arbitrage. Potential empirical evidence will only be able to arise a few years after implementation.
\end{abstract}

Keywords: portfolio choice, Basel Accords, derivatives.

JEL classification: $G 28, G 11, G 12$.

\section{Resumen}

El objetivo de la revisión fundamental del libro de negociación (2016) era superar las deficiencias conceptuales del antiguo marco prudencial, que se pusieron de manifiesto durante la crisis (2007-2012). En este artículo se describen los principales elementos de este nuevo marco, se comparan con el antiguo y se analizan en base a sus objetivos originales. En general, la mayor parte de los cambios e innovaciones tienen una robusta base teórica y, por tanto, un alto potencial para alcanzar los objetivos pretendidos, tal como aumentar la sensibilidad al riesgo, reducir la variabilidad indebida de los activos ponderados por riesgo o limitar el arbitraje regulatorio. La potencial evidencia empírica solo podrá surgir algunos años después de la implementación.

Palabras clave: elección de cartera, Acuerdos de Basilea, derivados.

Clasificación JEL: G28, G11, G12.

\section{Introduction: an international market risk framework}

In January 2016, the Basel Committee for banking Supervision (BCBS) published a new prudential framework for market risk, known as «The Fundamental Review of the Trading Book» (FRTB). The review of the market risk framework was one of the main objectives of the BCBS post-crisis reforms and work on this area started right after the crisis. However, and partly due to the complexity of issues at stake, the FRTB was released significantly later than the initial set of BCBS postcrisis reforms, such as the reform of the own funds framework or the introduction 
of the liquidity framework ${ }^{1}$. That leaves the FRTB, from a time perspective, in an intermediate position between the BCBS initial set of post-crisis reforms and the so-called «finalisation of the Basel III package», still under negotiation. The latter includes, among other things, the review of internal ratings-based approach for credit risk, the introduction of floors for model-based approaches and the reform of the operational risk framework. This package, although very much developed from a technical perspective, is still pending international agreement among the BCBS members.

The market risk framework in place at the time of the financial crisis dated from 1996 and was introduced as an amendment to the Basel Capital Accord (Basel I). During the crisis, trading book positions suffered huge losses, well beyond the prudential own funds requirements associated with these positions. As a result, there was a general conception that the market risk framework in place was not fit for purpose and that there was a need to review it. It is worth mentioning that the 1996 framework included both a standardised approach (SA) and an internal models approach (IMA). During the crisis, this IMA, as used by many big international banks, was considered one of the main elements contributing to the undercapitalisation of market risk positions. In this regard, there was a substantial difference with the credit risk framework in place at the time of the crisis. Internal approaches for credit risk were not introduced until 2005 (Basel II), and in most jurisdictions, they had not entered into force by the time of the financial crisis. Therefore, most of the criticism on the underperformance of internal approaches is linked to the old IMA. This general view on the inadequacy of market risk internal approaches together with the pressure for the BCBS to deliver something quickly led to a reform of the market risk framework, adopted in 2009, which only addressed the IMA. Furthermore, this reform did not modify the conceptual foundations of the existing approach, but simply introduced some additional elements to it with the main objective of increasing own funds requirements. In particular, the reform proposed the introduction of two additional capital charges in the IMA: one to capture default risk as a standalone risk independent from market volatility (IRC, Incremental Risk Charge) and one to better capture market volatility at times of financial stress (stressed VaR, Value at Risk).

Although this resulted in a significant increase in own funds requirements, there was the view that the conceptual shortcomings of the 1996 framework had not been addressed. This set in motion a more thorough process to review the whole framework (including the standardised approach and the boundary) which led to the FRTB. The main objectives of the FRTB, as stated in its first consultation paper ${ }^{2}$ (2012), were the following:

\footnotetext{
${ }^{1}$ The bulk of the BCBS post-crisis reform package embraced: the own funds and leverage ratio framework (2011), the Liquidity Coverage Ratio (2013) and the Net Stable Funding Ratio (2014).

${ }^{2}$ Basel Committee on Banking Supervision Consultative document Fundamental review of the trading book, May 2012.
} 
- A more objective boundary between the trading book and the banking book that materially reduces the scope for regulatory arbitrage;

- Moving from value-at-risk to expected shortfall, a risk measure that better captures «tail risk»;

- Calibrating the revised framework, both the standardised and internal models approaches, to a period of significant financial stress;

- Comprehensively incorporating the risk of market illiquidity, again consistent with the direction taken in Basel 2.5;

- Introducing measures to reduce model risk in the internal models-based approach, including a more granular model approval process and constraints on diversification; and

- A revised more risk-sensitive standardised approach that can act as a credible fall-back to internal models.

In the next sections, the different components of the final FRTB text will be described, compared to the previous framework and analysed against its initial objectives. From now on, when a reference to the «previous framework» is made, it will correspond to the one in place after the 2009 reform of the IMA approach.

\section{The revised boundary}

The existence of two separate books (banking book/trading book) in the previous framework, with different capital requirements and the possibility for some securities to be allocated to either one or the other, generated possibilities for regulatory arbitrage. The main criterion in the previous framework to allocate one position either to the trading or to the banking book was the trading intent. This means that the same instrument (a debt security) could in theory be booked in either of the prudential books, depending solely on he bank's intention towards that security.

This has a justification, since it could be argued that, for example, the same debt security would not pose the same risk for the institutions in either of these two cases. When a debt security is actively traded, it is by the definition only supposed to be kept short term and therefore there is the possibility that the position can be closed at any point in time, including when market fluctuations may have driven its price downwards. Accordingly, it must be fair-valued and any changes in its price have an actual and immediate impact on bank's profit and loss (regardless whether it is sold or not). Therefore, a specific capital framework to capture this day-to-day impact on profit and loss of trading positions seems adequate. In contrast to this, when the same debt security is held to maturity (and as a result allocated to the banking book for prudential purposes) it will not be exposed to the same risk of market fluctuations, since the bank will receive the cash-flows as foreseen unless the issuer fails to meet its obligation (in other words, unless it defaults). In such case, the credit risk framework seems more appropriate. 
This justification to have different prudential requirements for trading and nontrading activities is clear for some instruments, such as debt securities, but it may be less clear for others. Equity securities, for example, are fair-valued even if in the banking book, and options do not seem compatible with a «hold to maturity» perspective, which is normally linked to banking book exposures. Furthermore, the fact that the trading intent in the old framework was self-assessed by the bank, without further guidance in the regulation, could be arbitraged, with the purpose of seeking capital savings.

In the various FRTB consultation papers several options were discussed ${ }^{3}$. One of them was actually a no-boundary option. However, finally, the two book framework was kept, but with significant changes. These went in the direction of providing more objective rules on when a security had to be in the banking or in the trading book, with the objective to prevent regulatory arbitrage by banks. In particular, the following elements were added:

- A more explicit definition of trading intent, providing a list of activities which are assumed to entail trading intent. For example, instruments linked to market making or underwriting activities within the bank are presumed to belong to the trading book.

- A list of instruments that are assumed to belong either to the trading book or to the banking book; the so-called presumption list. Instruments such as listed equities or options are presumed to be allocated to the trading book. This stems from the fact that a banking book treatment would not seem appropriate for these securities in most cases and is regarded as something exceptional. Following the same logic, instruments such as unlisted equities or real estate holdings are presumed to belong to the banking book.

- A strict procedure to break these presumptions. If a bank believes that they have to deviate from these rules for a certain instrument, the bank must then submit a request to its supervisor and receive explicit approval.

- A less permeable boundary with stricter limits on switching between books (switching subject to strict supervisory approval) and measures to prevent a «capital benefit» in instances where switching has been allowed, in order to reduce the incentives for arbitrage.

All in all, it can be said that the reform makes significant progress towards the objective of achieving «a more objective boundary between the trading book and the banking book that materially reduced the scope for regulatory arbitrage» and is therefore clearly superior to the existing one. However, the actual impact of these rules will to a large extent depend on supervisory implementation. This is for example the case of the definition of trading intent. While including a list of activities with trading intent is a positive feature, determining whether the bank

\footnotetext{
${ }^{3}$ For example, a trading-evidence approach and a valuation-based approach
} 
is actually performing a given activity when trading the securities of (i.e. market making) requires a good deal of supervisory judgement. The way that judgement is exercised will shape the final result.

The presumption list, on the contrary, is supposed to provide more objective criteria (i.e., instrument which result from underwriting commitments are more easily identifiable, since these commitments are generally formal). However, even if the criteria are more objective, the fact that the rule has not been stablished as general obligation for institutions, but as a presumption, which can be waived by supervisors, makes its final impact also unclear. Moreover, there is no guidance in the FRTB on the reasons why supervisors may allow not to allocate these securities to the trading book. Therefore the final impact of this rule will also depend to some extent on how the rule is implemented in the different jurisdictions and on how supervisors enforce it.

\section{The standardised approach}

The need to revise the SA came mainly from the need to provide a credible fall-back for internal models. The old SA was not able to fulfil that objective, because of its lack of risk-sensitivity and of its capital impact, which was on average well above that of the IMA.

The lack of risk-sensitivity comes from the general design of the old framework, which can be described as a case-by-case approach. For each type of instrument (fixed income, equity, commodities, currencies, options), there was a specific «capital treatment» which had to be applied as a recipe. Therefore, the charge was made dependent on the main objective features of the instrument: type of instrument, maturity, coupon, dividend payments, rating, etc.

While this approach had the benefit of providing an objective set of rules applicable to all banks in the same way, it lacked abstraction, and hence, it did not work well for many instruments, especially for more complex ones. In other words: while under the old framework two banks trading the very same instrument would be subject to the same capital charge, it could also be that two banks trading two significantly different securities would also receive capital charge. That happens when instruments incorporate features that the framework does not properly capture, such as prepayment risk. This led to a lack of risk-sensitivity.

Regarding the level of own funds requirements under the old approach, the fact that this was so much higher under the SA than under the IMA made it extremely penal for a bank using models to turn to the SA.

This big cliff effect resulting from the potential change might have generated some reservations for supervisors to require banks to turn to the SA in cases where models did not perform adequately or did not fulfil some of the requirements, judging from the anecdotical available evidence on these mandatory changes. As a result, the lack of credibility of the threat probably reduced incentives for banks to model correctly. 
To fulfil the objective of achieving greater risk-sensitivity, the new SA has been designed following the logic of a model. However, its parameters are standardised and provided by the regulation. Furthermore, to fulfil the objective of creating a credible fall-back, these were calibrated following the same logic of the new IMA approach, with objective of making standardised requirements closer to IMA ones.

As far as the design is concerned, the new framework is more abstract and hence suitable for a much broader scope of instruments. It is based on the simple principle of reflecting the impact of standardised shocks in risk factors on the price of trading instruments.

These shocks are applied to the whole trading portfolio. Depending on the type of instruments the bank has, it may be immune to some of these, but the framework does not pre-judge when that would happen.

In order to be able to achieve this degree of abstraction, the framework has to rely on an element which is however bank-specific: the pricing model used to price the securities. On the one hand, this may lead to a situation in which banks holding exactly the same instruments may not be subject to the exact same capital charge, unlike in the old approach. Potential variability will depend on the specific, different pricing models used by each bank for the same instrument. On the other hand, the framework will be better able to capture differences in risk-features of instruments even if they do not have an ad-hoc treatment in the regulation, since these will be already embedded in the pricing model of the instrument. These can be, for example, the effect of prepayment features which was referred to before or simply a different time distribution of coupon payments of a debt security, which is not properly captured by the old framework. The different risks arising from these features will be automatically captured through the pricing model, without the need for ad-hoc prudential rules and specifications. As a result, the capital charge will be both more accurate and more comprehensive of the different risks an instrument is exposed to.

Its downside, the potential variability due to the use of different pricing models, should be negligible. All these pricing models should be the same ones used for accounting purposes, and as such should be validated by the auditor and the accounting supervisor. Therefore, it is assumed that all of them, even if different in their design, will be fit for purpose and provide a good outcome.

\subsection{Main elements}

The new SA is composed of three distinct capital charges, whose purpose is to capture the different manifestations of market risk:

a) Sensitivities-based capital charge

b) Default risk

c) Residual risk add-on 


\section{General rationale of the sensitivities-based capital charge}

This is the main element of the SA and it is meant to capture the pure market risk, i.e. the risk arising from fluctuations in market prices. As explained before, instruments are subject to a series of standardised shocks which relate to a finite number of risk factors. Which of these shocks in risk factors are applicable to each instrument will depend solely on the pricing model of the instrument. If the pricing model recognises a risk factor as a driver of the price of the instrument, the effect of shocking that risk-factor on the price of the instrument will need to be calculated and will feed into the capital charge.

The risk factors are grouped into the following risk classes: interest rate and inflation risk, equity risk, credit spread risk, commodity risk and foreign-exchange risk. In turn, within each of these risk-classes, there is a breakdown by «buckets» according to the economic sector or counterparty of the instrument, for each of which a specific shock is prescribed. Even if for two differents instruments in the same bucket the applicable standardised shock is the same, the capital charge resulting from shocking that risk factor in each of the instruments can be very different depending on the sensitivity of the security to the risk factor. For example, let us imagine two debt securities, which are, as such, are subject to interest rate risk with maturity of one year. For both, the risk factor 1-year risk free rate (for example, euribor) will be applied, since it will be a driver of its price. The shock will be the same in both cases: a movement in this rate of 300 basis points. However, if one of the two is a zero-coupon bond and the other pays quarterly coupons, the zero coupon bond will be more sensitive to movements in this risk factor rate and the effect of the shock on the price will be hence much more intense.

In practice, the framework does not calculate the full effect of each shock on the price of the instrument, but works with an approximation. The full effect would be the one resulting from repricing the instrument after the risk factor (for example the 1-year risk free rate) is shocked. While this would be more accurate, it would be very intensive in terms of calculation, especially if the effect of the shock has to be calculated and aggregated for thousands of instruments, as it normally occurs. Alternatively, what the framework does is to work with the so-called sensitivities. The sensitivity is no more than a first order derivative for each risk defined as «the price change in an instrument due to an infinitesimal change in one of its variables (risk-factors)».

Operationally, the first step is actually the calculation of the sensitivities. Only once the sensitivities of all instruments in the bank's trading book affected by the same risk factor are calculated, they are aggregated and netted (positive with negative) and finally applied the above mentioned shocks (a single shock per risk factor is applied to this «net» sensitivity). The assumption that this method entails is that pricing functions are linear, although, this is not frequently the case. The error due to non-linearity is considered negligible in all instruments different from options. 


\section{The sensitivity-based capital charge in the case of options}

In the case of options, although the same general framework as for the other instruments applies (i.e. sensitivities to different risk factors are calculated, netted and shocked), there are two important specific features.

The first one is that there is one additional risk-factor for all options: the volatility. As a result, every option will be at least subject to two risk factors: one linked to the underlying and another one linked to the volatility of that underlying. However, the calculation and aggregation methodologhy will be the same as for any other risk factor: the sensitivity to the volatility (vega) will be calculated for each option an aggregated to that of other options sensitive to the same underlying.

The second one is a feature which strives to correct the assumption of linearity of the pricing function. For this purpose, a gamma-correction is incorporated, under the name of «curvature risk». This consist on calculating for every risk factor an additional capital charge in cases where the pricing model indicates that the (linear) shock specific to this risk factor is underestimating the actual decrease in the price of the option as a result of the shock. As such, this correction is asymmetric. This means that it will add a capital charge when the linear shock underestimates the price decrease, but it will not result into a capital relief when the shock overestimates it. However, this asymmetry seems to be intentional, on the grounds of a more prudent treatment.

\section{Hedging and diversification effects in the sensitivities-based capital charge}

Another new feature of the sensitivities-based approach compared to the old framework is its ability to capture diversification effects among different instruments. As a result, the final market risk capital charge will not only depend on the standalone securities, but also on the composition of the trading book. In this regard, it is very different from the previous framework. Whereas both frameworks take into account «perfect hedges», (short and long positions always offset and capital charges are calculated over net positions), in the old framework there is no recognition of imperfect hedges or diversification. In the old framework, the overall capital charge is obtained simply by adding all individual capital charges.

In contrast to this, in the FRTB, the aggregation methodology takes into account to a certain extent the correlation among the different risk factors in the portfolio of an institution. A formula which considers the correlation parameters among riskfactors prescribed by the FRTB must be used to aggregate the individual capital charges from the different risk factors.

$$
K_{b}=\sqrt{\sum_{k} W S_{k}^{2}+\sum_{k} \sum_{k \neq l} \rho_{k l} W S_{k} W S_{l}}
$$


Where $W S_{k}$ is the capital charge linked to the risk factor $k, W S_{l}$ is the capital charge linked to the risk factor $l$ and $\rho_{k l}$ represents the correlation between this pair of risk-factors. As long as some correlations are lower than one, it follows that $K_{b}$ will be lower than the simple sum of individual capital charges.

However, hedging and diversification are only considered among risk-factors within same risk-class. For example, correlations between risk-free rates of different maturities will be considered when aggregating the capital charges linked to each of these interest rate risk-factors. However, capital charges resulting from different risk-classes, for example between interest rate and equity risk, will be just added up with no diversification benefits (in other words, assuming a correlation equal to 1 between them).

\section{The default risk charge}

The default risk charge is a standalone capital charge which is meant to capture the jump to default risk of trading securities. In general terms, this charge is meant to capture the same risk as the credit risk charge of the banking book. The fact that securities are traded does not isolate them from the risk of a default of the issuer, which can drive the value of the security to zero, or a very low amount, in one single step and not gradually.

However, there are two very important differences between credit risk in the trading and in the banking book, which are well reflected by the FRTB. The first one is that the holding period of securities in the trading book is generally lower than in the banking book. A lower holding period decreases the probability of a default event taking place during this holding period. Therefore, it would be disproportionate to generally require a capital charge equal to that of the banking book. The FRTB takes this perspective into consideration and introduces a credit quality step calibration of risk charges which is less conservative to that of the banking book. Moreover, scaling down for instruments with maturities shorter than 1 year is introduced. The second difference is the fact that some of the losses due to a default event may already be losses reflected in fair value of the instrument at the time of default. Therefore, an adjustment in default risk charge is made to take into account already accrued losses, by reducing the loss-given-default component accordingly.

A parallel between the old and the new framework in this regard is not obvious. The old framework incorporated the so-called general and specific risk capital charges. In the case of debt securities, the general risk could be conceptually assimilated to that resulting of risk-free interest rate risk factors in the sensitivities based approach. The specific risk charge, however, cannot be automatically assimilated to the default risk charge only, since the sensitivities-based approach also introduces a charge for «credit spread risk». Therefore, the credit risk of the issuer in the new framework is in fact decoupled into two: a default risk charge and a credit spread risk charge. Therefore, it could be argued that the old specific risk-charge would comprise both the credit spread risk charge and the default risk charge of the FRTB. 
A long debated question is the relationship between these two charges and whether there is an overlap between them. Strictly speaking, changes in credit spreads reflect changes in the expected loss from default and hence follow the probability distribution of expected losses from default. In contrast to this, the default risk charge is supposed to cater for actual losses in the event of a jump to default and is calibrated according to the probability distribution of actual losses.

\section{The residual risk add-on (RRAO)}

This is a new capital charge for which there is no equivalent in the old standardised approach. The purpose of this charge is to create a capital charge for instruments bearing risks that the sensitivities based approach is not able to capture. This third component of the standardised approach is not meant to be an alternative, but an additional component of the SA (i.e. an instrument subject to the RRAO is not generally exempted from the rest of the charges in the SA). However, in the case of many instruments in scope of the residual risk add-on, the calculation of the capital charge according to the sensitivities based approach or the default risk charge will just not be possible and the RRAO may in practice be the only capital charge for these instruments.

The FRTB establishes two different cases of instruments subject to the RRAO, which are assigned accordingly a different levels of own funds requirements. The first one comprises derivatives with exotic underlyings which are defined as those not sensitive to any of the risk-factors listed in the FRTB. These are, for example, weather derivatives, derivatives on natural disasters or derivatives bearing longevity risk. For these instruments, it is simply not possible to calculate a capital charge according to the sensitivities-based approach framework and the RRAO will be the standalone capital charge.

The second case comprises «instruments with other residual risks», according to the FRTB. This refers to two sets of instruments. The first case refers to instruments in the scope of the correlation trading portfolio. The second one refers to exotic options, which are defined as those «cannot be written as a linear combination of plain vanilla options». The latter case includes, for example, Asian options or barrier options. For many of these options delta, gamma or vega are often discontinuous, their value can exhibit abrupt changes in their sign, or its estimation may not even be possible. Therefore, a capital charge based on these «greeks» (as in the sensitivitiesbased approach) will not give a meaningful estimation of the level of capital required for that option. However, the most straightforward interpretation of the FRTB is that, whenever it is possible to calculate the sensitivities-based approach charge, it shall still be calculated ${ }^{4}$, and the RRAO shall be added on top, when required.

\footnotetext{
${ }^{4}$ There is only an exemption for multi-underlying options delta sensitivities have different signs.
} 
As regards the level of the capital charge, it is far bigger for exotic underlyings than for other residual risk. This is logical, in the first place because, as explained before, the former will most probably not be subject to any other capital charge within the standardised approach. But also because the risk embedded in these instruments is far more difficult to foresee and to model.

\subsection{Assessment and potential challenges}

In general, we can say that the new standardised approach sets a far more risk sensitive and comprehensive framework for market risk than the old approach. However, a number of remarks can be made.

First, regarding the objective of providing a risk-sensitive framework, this more sophisticated framework is not able to avoid the introduction of the residual risk add-on, which in essence is a way to take into account a risk that the framework is not able to measure. Moreover, the capital charge linked to this risk is set as a blunt fixed percentage of the fair value of the securities. Although in principle this does not seem a very good solution, all in all, it strikes a good balance between simplicity and risk-sensitivity. The introduction of a wider set of risk factors and capital charges would, in the end, not have been able to capture all types of exotic options or derivatives with exotic underlyings. Therefore, doing so would probably not have eliminated the need for a RRAO, but only narrowed its scope, at the cost of introducing far greater complexity in the rest framework.

Second, the increase in risk sensitivity due to the use of different pricing models might come at the cost of higher risk-weight variability. Indeed, pricing models used by banks can differ and this could, in theory, lead to very different capital charges. However, in practice, since these models are also used for accounting, they have to be checked by auditors and, often, by banks' accounting supervisors. Therefore, even if the specifications of these models differ, they should all perform well and lead to broadly similar results.

Third, and linked to the objective of serving as a fall-back to internal models, the calibration of the large number of parameters embedded in the standardised approach requires further refinement and update. In addition to the operational difficulty of estimating all these parameters in a balanced, proportionate manner, some of these parameters, such as correlations, change over time and they should be frequently updated.

As a safeguard, the FRTB contains a «review» clause and the calibration of some parameters could be revised in the coming future. A more accurate calibration should be easier to achieve once the framework is implemented, since it can be based on the actual impact. Furthermore, in the case of correlation parameters in the SA, there is an additional safeguard in place, aimed at addressing the margin of error. This consists in the obligation to perform the aggregation of capital charges according to three scenarios: medium, low, high and medium correlation scenarios. The FRTB 
prescribed correlations are used for the medium correlation scenario and they are downscaled or upscaled in order to provide with the correlations to be used in the low and high correlations scenarios respectively. The scenario leading to the highest figure will be the only one considered to quantify the capital charge. This provides for a good cushion for potential variability in correlation parameters.

\section{The Internal Models Approach (IMA)}

In terms of general structure, the new IMA is similar to the old one, despite the multiple innovations. Therefore, for the IMA, it is easier to establish a parallel with the old approach than it is for the SA. As in the old one, there is one capital charge to capture the risk of variability in market prices, the expected shortfall model, which substitutes the old Value at Risk (VaR) charge. On top of that, there is one charge aimed at capturing default risk, the default risk charge (DRC), which substitutes the old incremental risk charge (IRC). The only distinct new element, which does not find a clear parallel in the old framework, is the capital charge for non-modellable risk factors.

Despite that, there is one significant overarching change as regards the scope of the models and the model approval. In the FRTB, it is the standalone desk, as opposed to the whole portfolio, that constitutes the central element for IMA requirements. Consequently, model approval has to be requested at desk level and, in the same way, the removal of model approval will only affect a specific desk, but not the whole trading book of an institution. This has a number of benefits. In the first place, this should facilitate the identification of the relevant risk factors in a particular desk, making it more accurate. Secondly, it should allow a more granular monitoring of model performance, since the quantitative tests to grant and to keep model approval are performed at the trading desk level.

Also, a specific regulatory tool has been introduced to monitor the performance of the model at desk level: the profit and loss (P\&L) attribution. In essence, P\&L attribution is a measure which tries to assess the accuracy and explanatory power of the model. It compares a P\&L measure based on the actual profit and loss of the desk (hypothetical P\&L, which reflects changes in portfolio value that would occur were end-of-day positions to remain unchanged) with the P\&L that would be produced by the bank's pricing models for the desk if they only included the risk factors used in the risk management model (risk theoretical $\mathrm{P} \& \mathrm{~L}$ ). If deviations are beyond certain thresholds, model approval will not be granted or will be removed.

The framework also keeps the existing backtesting of the old approach, which is now applied at desk-level. Backtesting tries to assess the conservativeness of the model. As such, it compares actual daily losses in the desk with their respective daily VaR levels as forecasted by the model. If the former exceed the latter by more than specific number of times within a year, model approval may not be granted or may be removed. 


\subsection{Main elements}

The IMA has several elements which should be studied in detail, in order to understand how it works:

a) Expected shortfall model.

b) Default risk charge.

c) Non-modellable risk-factors.

d) Liquidity horizons.

\section{Expected shortfall model}

A fundamental change of the FRTB is the change in the statistical metric used to determine the level of capital requirements in the IMA approach, which goes from VaR to Expected Shortfall (ES). This shift does not necessarily entail a different modelling technique, but just introduces a different metric as regards the level of capital which is required given the P\&L probability distribution forecasted by a the model. The rationale behind the VaR metric is that a bank should have enough capital to face trading losses which may occur up to a specific confidence level. Hence, all losses beyond the confidence level are ignored for the calculation of the capital charge, regardless their level or probability or occurrence

However, in some cases, these may be very relevant to assess the risk profile of the instrument. There can be, for example, two different instruments leading to the same VaR level and hence with the same resulting capital charge under the old IMA, but which present a very different probability distribution of losses beyond the confidence level. One may, for example, follow a normal distribution. In this case, beyond the confidence level, ever higher losses will be assigned ever lower probabilities. The other may present a probability distribution wich diverges from the normal and in which some extreme losses may be assigned a far higher probability of occurrence than they would have in a normal distribution. Therefore, the overall riskyness of the latter instrument can be considered higher, despite the fact that both are assigned the same capital charge. This had an implication for trading losses during the crisis. VaR systematically underestimated losses for instruments which had probability distributions deviating from the normal one and hence presented substantial «tail risk».

The ES metric is intended to address this issue. The ES is in essence a conditional expected value, the expected value of losses conditional to losses being beyond the confidence level. The determination of the ES level can be described as a two-step process. A first step would be to set a confidence level, in the same way as for the VaR. But while for the VaR, losses corresponding to that confidence level are already the sole input used to determine the capital charge, for the ES it is only a starting point. The ES considers all losses beyond the confidence level as a single standalone probability distribution and it calculates the average loss of that distribution. 
Therefore, the distribution of losses beyond the confidence level is also relevant for the calculation of the final capital charge.

By taking the same confidence level as in the VaR, ES would always lead to a higher capital charge. However, that was not the intention of the FRTB. Therefore, a lower calibration was envisaged for the ES: 97,5 per cent instead of the 99 per cent of the current VaR. The underlying rationale of this calibration was to equate ES and VaR values in the case of a normal distribution.

Another important new feature of the ES model compared to the old VaR model is that it incorporates the potential effects of market stress into the calculation of the charge. Instead of having two separate capital charges as in the old framework, VaR and stressed VaR, which were additive, the specification of the ES charge incorporates the effects of market stress as a single figure.

\section{Default risk charge (DRC)}

The default risk charge mirrors the existing incremental risk charge (IRC). The FRTB consultation papers reflect that there was some discussion as to whether keeping a standalone model for default risk (the status quo) or introducing default risk as a risk factor in the ES model, but finally the former option was chosen. The DRC however has a number of features which are aimed at meeting the objective of restricting model freedom. As such, its specification is more detailed than the IRC model, containing, for example, more detailed rules on how to recognise the impact of correlations between defaults among obligors. In addition, it implements a floor for probabilities of default (PDs), which is set at a level of 0,03 per cent. A PD floor did not exist in the IRC framework, unlike in the existing internal approach for credit risk.

\section{Non-modellable risk-factors}

Another contribution to the objective of constraining undue model variability comes from the data quality requirements to include risk factors as variables in a model. Unlike the very generic requirements under the old framework, the FTRB introduces specific rules regarding the quality and number of observations needed to consider a risk factor modellable and prevents banks from using these risk-factors as variables in a model when these requirements are not met. In particular, according to the FRTB, «for a risk factor to be classified as modellable there must be continuously available real prices for a sufficient set of representative transactions». On whether a price is considered real or not, there is also a specific set of rules: 
- It is a price at which the institution has conducted a transaction;

- It is a verifiable price for an actual transaction between other arms-length parties; or

- The price is obtained from a committed quote.

If the price is obtained from a third-party vendor, where: (i) the transaction has been processed through the vendor; (ii) the vendor agrees to provide evidence of the transaction to supervisors upon request; and (iii) the price meets the three criteria immediately listed above, then it is also considered to be real.

On whether there is a sufficient set of representative transactions, the FRTB requires that a risk factor «must have at least 24 observable prices per year (measured over the period used to calibrate the current expected shortfall model) with a maximum period of one month between two consecutive observations».

When these requirements are no met, the risk-factor will be classified as nonmodellable and, instead of being capitalised through the model, it will be subject to a specific capital charge for non-modellable risk factors. In particular, the FRTB says that each non-modellable risk-factor is to be capitalised using a stress scenario that is calibrated to be at least as prudent as the expected shortfall calibration used for modelled risks. It also gives some rules on the correlations to be used among risk-factors. However, compared to other sections of the FRTB, the methodology to capitalise non-modellable risk factors is left very open.

\section{Liquidity horizons}

Towards the objective of contemplating the risk of market-illiquidity, the FRTB introduces the so-called «liquidity horizons». In this regard, it is good to remind that the FRTB is a capital standard and as such, aimed at addressing risks to the solvency of the institutions and not liquidity risks, unlike the liquidity coverage ratio or the net stable funding ratio. Therefore, the liquidity risk of an instruments will only be relevant for the FRTB insofar it has implications for its P\&L.

The ES measure incorporates the potential implications for P\&L arising from the liquidity of an instrument. As discussed above, the ES measure is an statistical measure, which is applied to the probability distribution of $\mathrm{P} \& \mathrm{~L}$ of an instrument or a portfolio. However, this probability distribution must be, by nature, linked to a time horizon: the variability of the portfolio or the instrument will be higher or lower depending on the time period which is considered. For the FRTB, this time period should be linked to the average holding period of an instrument by an institution. Following this logic, closing a position in the case of a less liquid instrument will generally take longer than in the case of a more liquid one and, as long as the position stays open, variability will have an impact on the P\&L of the institution. The «liquidity horizons» are designed to address this issue and thus assign longer holding periods to instruments which are deemed less liquid. In this regard, it takes over the logic 
from the liquidity standards of pre-defining the liquidity of an instrument directly in the standard and according to the type of instrument, counterparty or economic sector.

In the old framework, the concept of liquidity horizon for the calculation of VaR and IRC charges existed already, since it is a necessary element for the calculation of these charges. However, its relationship to liquidity is not clearly established. In the case of VaR, it just consisted of a fixed period of 10 days, common to all instruments. In the case of the IRC, some discretion is left to institutions to determine the holding period according to the liquidity of the instrument, but subject to a floor.

\subsection{Assessment and potential challenges}

In general, the proposed changes to the IMA meet adequately the objectives which were set originally.

In the first place, its capability to capture tail-risk is strongly enhanced by the use of ES. The stressed calibration is incorporated into the model in a sounder and more comprehensive way, which leads to a final ES figure.

In the second place, the risk of market illiquidity is also well reflected through the liquidity horizons. However, the fact that the liquidity level is predefined, although consistent with other regulations and standards, may entail that at some point it in time it does not accurately reflect the actual liquidity of some instruments, since liquidity levels can change quickly.

In the third place, the measures to reduce model risk are comprehensive: input floors, qualitative and quantitative requirements to model risk-factors, clearer requirements on the design of the model, desk-level specification of models and more stringent requirements on model performance. All of them taken together should have a significant impact on reducing undue model variability, although empirical evidence may only become available after implementation.

Finally, and even if not among the main objectives, the framework is also mindful of reducing the operational burden for banks. In this regard, there are some features which were introduced to simplify its application. Among them, for example, the number of risk-factors for which a «stressed calibration» is necessary is smaller than the full set of risk factors necessary for the specification of the model. Also, the actual application of liquidity horizons does not require a new ES calculation for each liquidity horizon level, but allows an interpolation from the baseline 10-day liquidity horizon.

\section{The implementation of the FRTB in European legislation}

In November 2016, the European Commission published a legislative proposal to amend the Capital Requirements Regulation (CRR) which included a number 
of important features, among which the implementation in EU law of a number of Basel standards, including the FRTB.

The proposed implementation of the FRTB is very faithful to the original standards and only few adjustments are envisaged. We can divide them into two categories:

1. Adjustments to calibration. First of all, there is one major horizontal adjustment to the calibration of the whole framework. By virtue of article 500 of the CRR proposal, there is a rebate of 35 per cent on all FRTB capital requirements, both to those in the IMA approach and in the SA. This rebate is limited to three years, after which the European Commission shall decide, via delegated legislation, to extend the benefit, not to do it, or to revise the above mentioned factor. Bearing in mind the average increase in requirements estimated by the BCBS impact study, this rebate may neutralise the average impact of the new market risk requirements, leaving requirements at a level close to its current one, on average. Secondly, the CRR also makes some targeted adjustments to calibration. This is the case, for sovereign exposures and for covered bonds, which are subject to targeted adjustments both in the IMA and the SA.

2. Special framework for small trading books. The Commission proposal introduces a simplified framework for banks with small trading book. As result of the increase complexity of the new SA, which would otherwise be the default approach for these banks. This framework follows a threetier approach, in which complexity increases with the size of the trading books. The first tier, which is the simplest approach for trading books (those below 20 million) is the so-called derogation for small trading books. This derogation existed already in the currently applicable CRR, and consists in practice of allowing the application of the banking book capital framework to trading book instruments. In the Commission proposal, the threshold for the derogation is increased and some technical adjustments are made. However, the applicability of banking book rules to certain instruments, such as options, still raises some questions. The second tier (for trading books below 300 million) is the so-called simplified standardised approach, which is nothing else than the current standardised approach. The third tier, for banks over 300 million, is already the new standardised approach.

In addition to the absolute thresholds mentioned above, in order to be able to use one of the simplified approaches, the bank must also fulfil specific relative thresholds. This means that, even if the bank's trading book is small in absolute terms, but trading activities are above a specific share of the balance sheet ( 5 per cent and 10 per cent for the tier 1 and 2 respectively), the bank will not be able to use the simplified approaches.

The simplified approaches are however not mandatory, a bank below the thresholds may always choose to use the more sophisticated approaches, or can even 
use them only for a share of its portfolio. However, partial use of the simplified standardised approaches and the IMA approach is not allowed.

Finally, some areas of the FRTB, such as the treatment of non-modellable risk factors or backtesting, are referred to delegated legislation in the form of Binding Technical Standards of the European Banking Authority.

\section{Conclusions}

The Fundamental review of the trading book introduces wide-ranging changes in the boundary, the standardised approach and the IMA for market risk. All these changes and innovations, like the use of ES or instrument-specific sensitivities, are based on sound theoretical grounds and hence have a strong potential to contribute to achieving the objectives of the reform. However, the practical impact on achieving some of its objectives, such as on the reduction in risk-weight variability or in regulatory arbitrage related to the boundary, will only be seen after testing data corresponding to a period after implementation. Furthermore, there are some features of the reform which may also pose some challenges for the implementation itself and may as well have an impact on the final result. These are, for example, the boundary provisions, where the Basel text leaves some room for interpretation and for supervisory or jurisdictional discretion or the NMRF charge, whose calculation methodology is left very open.

\section{References}

[1] BASEL COMMITTEE FOR BANKING SUPERVISION (1996). Amendment to the capital accord to incorporate market risks, Basel. http://www.bis.org/publ/bcbs119.htm

[2] BASEL COMMITTEE FOR BANKING SUPERVISION (2009). Revisions to the Basel II market risk framework, Basel. http://www.bis.org/publ/bcbs158.htm

[3] BASEL COMMITTEE FOR BANKING SUPERVISION (2011). Basel III: A global regulatory framework for more resilient banks and banking systems, Basel http://www. bis.org/publ/bcbs189.htm

[4] BASEL COMMITTEE FOR BANKING SUPERVISION (2012). Consultative document: Fundamental review of the trading book, Basle. http://www.bis.org/publ/bcbs219.pdf

[5] BASEL COMMITTEE FOR BANKING SUPERVISION (2012). International Convergence of Capital Measurement and Capital Standards. A Revised Framework, Basel. http://www.bis.org/publ/bcbs107.htm

[6] BASEL COMMITTEE FOR BANKING SUPERVISION (2013). Consultative Document Fundamental review of the trading book: A revised market risk framework, Basel. http://www.bis.org/publ/bcbs265.pdf

[7] BASEL COMMITTEE FOR BANKING SUPERVISION (2014). Fundamental review of the trading book: outstanding issues-consultative document, Basel. http://www.bis. org/bcbs/publ/d305.htm 
[8] BASEL COMMITTEE FOR BANKING SUPERVISION (2016). Minimum capital requirements for market risk, Basel. http://www.bis.org/bcbs/publ/d352.htm

[9] EUROPEAN COMMISSION (2016). Proposal for a Regulation of the European Parliament and of the Council amending Regulation (EU) No 575/2013 as regards the leverage ratio, the net stable funding ratio, requirements for own funds and eligible liabilities, counterparty credit risk, market risk, exposures to central counterparties, exposures to collective investment undertakings, large exposures, reporting and disclosure requirements and amending Regulation (EU) No 648/2012, Brussels. https:// ec.europa.eu/transparency/regdoc/rep/1/2016/EN/COM-2016-850-F1-EN-MAIN.PDF

[10] ACERBIA, C. y TASCHEB, D. (2002). «On the coherence of expected shortfall». Journal of Banking \& Finance, 26 (7), 1487-1503.

[11] HAHN C.; PFINGSTEN A. y WAGNER P. (2001). «Assessing the Risk of Trading Books Empirically: Does the Choice of a Risk Measure Matter?». In: H. U. Buhl, N. Kreyer and W. Steck (eds.), e-Finance. Springer, Berlin, Heidelberg. 